\title{
Cistična hidatidna bolezen pri otroku: prikaz primera
}

\section{Cystic Hydatid Disease in a Child: Case Report}

Petra Golob, Katja Zemljarič, Jernej Brecelj

\section{Izvleček}

Cistična ehinokokoza ali hidatidna bolezen je široko endemična parazitoza, ki jo povzroča okužba z jajčeci trakulje Echinococcus granulosus. Kaže se lahko z različno klinično sliko, ki je odvisna od velikosti ciste in od organa, v katerem se tvori. $\vee 70 \%$ se pojavi v jetrih. Diagnozo potrdimo $\mathrm{s}$ serološkim testiranjem protiteles proti hidatidnim antigenom ter s slikovnim diagnosticiranjem (UZ ali CT/MRI). Metode zdravljenja vključujejo zdravljenje $z$ albendazolom in/ali kirurške pristope, vključno s perkutano transhepatično sklerozacijo. Na uspešnost zdravljenja vplivata stopnja jetrnih cist in njihova umeščenost. Cistična ehinokokoza lahko poteka brezsimptomno, a obstaja veliko tveganje ponovitve. Pomembno je, da pri diferencialni diagnozi cističnih sprememb na jetrih pomislimo na okužbo $z$ ehinokokom. Prikazujemo primer slučajno odkrite bolezni pri brezsimptomnem dečku.

Ključne besede: hidatidna cista, parazitoza, Echinoccocus granulosus, pediatrija.

\begin{abstract}
Cystic echinococcosis or hydatid disease is a widely endemic parasitosis caused by infection with eggs of the Echinococcus granulosus tapeworm. The symptoms and clinical picture can vary, depending on the size and location of the cyst. In $70 \%$ of cases, the cyst formation occurs in the liver. The diagnosis is confirmed by serological testing for antibodies against hydatid antigens and by ultrasound or CT/MRI imaging. Treatment methods include chemotherapy with albendazole and/or surgical approaches, including percutaneous transhepatic sclerotherapy. The success of these methods is influenced by the stage and location of the hepatic cysts. However, cystic echinococcosis can be clinically silent and has a high recurrence risk. It is important to consider echinococcal infestation in the differential diagnosis of cystic liver lesions. We present a case of incidentally diagnosed disease in an asymptomatic boy.
\end{abstract}

Key words: hydatid cyst, parasitosis, Echinococcus granulosus, paediatrics. 


\section{Uvod}

Ehinokokoza ali hidatidna bolezen je parazitoza, ki povzroča hidatidne ciste $v$ jetrih ali drugih organih. Okužba z ehinokokom prizadene ljudi vseh starostnih skupin, najpogosteje otroke in mladostnike. Pri otrocih so največkrat prizadeta pljuča in jetra (1-3). Najpogosteje jo povzroča ehinokok ali pasja trakulja. Na svetu je najbolj razširjena vrsta trakulje, ki se prenaša na človeka. Najbolj prizadeta območja so Mediteran, Severna in Zahodna Afrika, države Srednjega vzhoda, Avstralija, Južna in Osrednja Amerika ter vzhodna Evropa $(2,4,5)$.

Značilno klinično sliko cistične hidatidne bolezni povzroča vrsta Echinococcus granulosus (2) ter je odvisna od prizadetega organa in velikosti ciste. Večina hidatidnih cist je brezsimptomnih in lahko spontano izginejo (3), ob znotrajtrebušnem razlitju ciste pa lahko nastopi anafilaktična reakcija ali nenadna smrt (2). Diagnozo postavimo na podlagi klinične slike ter slikovnih in seroloških preiskav (3). Bolezen zdravimo samo $z$ albendazolom ali $v$ kombinaciji s perkutanimi intervencijskimi posegi ali kirurškim zdravljenjem.

$\checkmark$ prispevku predstavljamo primer dečka z naključno ugotovljeno hidatidno cisto jeter.

\section{Prikaz primera}

Oseminpolletni deček je bil obravnavan $v$ gastroenterološki ambulanti Pediatrične klinike Ljubljana zaradi naključno ugotovljene ciste na jetrih. $\checkmark$ gastroenterološko ambulanto so ga napotili pulmologi, ki so ga obravnavali zaradi ponavljajočih se levostranskih pljučnic ter režasto zoženega sapnika in levega glavnega bronha. $Z$ računalniško tomografijo (CT) pljuč, s katero niso uspeli ugotoviti vzroka zožitve v spodnjem delu sapnika, so naključno prepoznali cistično spremembo na jetrih. Deček ni imel nobenih simptomov s strani prebavil. $Z$ ultrazvočno
(UZ) preiskavo trebuha so ugotovili $35 \mathrm{~mm}$ veliko okroglo kolesasto tvorbo $v 6 / 7$ segmentu jeter brez hiperemije in značilnega videza. Pregled drugih organov ni pokazal odstopanj od normalnih vrednosti. $V$ laboratorijskih izvidih krvi je odstopala eozinofilija $(5,2 \%)$. Odvzeli so mu serologijo na ehinokokno okužbo. Presejalni test na Echinococcus sp. IHA je bil pozitiven (1:512), zato so opravili tudi potrditveni test Western blot, ki je bil prav tako pozitiven. Po posvetu z infektologom so uvedli zdravljenje $z$ albendazolom v odmerku 2 x $400 \mathrm{mg}$ dnevno za obdobje 4 tednov. Na kontrolnem pregledu smo ugotovili blago povišane vrednosti ALT $(1,29 \mu \mathrm{kat} / \mathrm{l})$ in normalne vrednosti eozinofilcev, deček pa ni navajal nobenih težav. Svetovali so mu 14-dnevno prekinitev zdravljenja $z$ albendazolom in nato ponovno 4-tedensko zdravljenje. Po dveh mesecih in dveh ciklih zdravljenja ob ponovnem UZ kontrolnem pregledu trebuha nismo zaznali dinamike. Deček je navajal prehode jutranje slabosti. V kliničnem statusu razen prekomerne telesne teže ni bilo odstopanj od normalnih vrednosti, laboratorijski izvidi krvi, vključno s hepatogramom, sečnino in kreatininom, pa so bili v mejah normalnih vrednosti. Po posvetu z infektologi smo dečka predstavili interventnemu radiologu zaradi nadaljevanja zdravljenja s perkutano transhepatično sklerozacijo hidatidne ciste. Štirinajst dni pred posegom so ponovno uvedli 4-tedenski cikel zdravljenja z albendazolom. Pred preiskavo je opravil UZ preiskavo trebuha, ki je pokazala nekoliko manjšo, $24 \mathrm{~mm}$ veliko cistično spremembo $z$ zadebeljeno steno in vključki zraka $v$ desnem jetrnem režnju. V splošni anesteziji smo opravili perkutano transhepatično sklerozacijo pod UZ nadzorom, a s punkcijsko iglo nismo uspeli pridobiti tekočine, zato smo uvedli $8 \mathrm{~F}$ drenažni kateter, preko katerega smo cisto izpraznili, sprali in sklerozirali z $10 \mathrm{ml}$ absolutnega alkohola. Z mikrobiološko preiskavo punktata smo dodatno potrdili okužbo s povzročiteljem Echinococcus granulosus. V laboratorijskih izvidih smo ugotavljali porast vnetnih parametrov (CRP 143, PCT 0,52), klinično pa je bila pri dečku prisotna mrzlica. Ob porastu vnetnih parametrov smo tretji dan uvedli intravensko zdravljenje $\mathrm{z}$ amoksicilinom s klavulansko kislino v odmerku 1,2 g/6 h. Deček je prejemal tudi redno analgetično zdravljenje (paracetamol ter dodatno naproksen in metamizol ob prebijanju bolečine). Kljub povečevanju vrednosti vnetnih parametrov s kontrolnim UZ pregledom trebuha nismo uspeli dokazati akutnega vnetnega dogajanja v trebušni votlini. Cista z zadebeljeno steno je bila še vedno prisotna, a po sklerozaciji napolnjena z zrakom. Po intravenskem antibiotičnem zdravljenju je prišlo do kliničnega izboljšanja, znižanja povišane telesne temperature in zmanjšanja vrednosti vnetnih parametrov. Po posvetu $z$ infektologom je deček nadaljeval z antibiotičnim zdravljenjem z amoksicilinom s klavulansko kislino doma, skupaj 14 dni. Nadaljeval je tudi s ponovnim, tokrat četrtim 4-tedenskim ciklom zdravljenja $z$ albendazolom. En teden po odpustu iz bolnišnice je opravil laboratorijski kontrolni pregled jetrnih testov. Po enem mesecu je pri izbranem pediatru opravil kontrolni UZ trebuha. Ugotavljali smo približno enako velikost ciste $29 \mathrm{~mm} \times 23 \mathrm{~mm}$ x $23 \mathrm{~mm}$. Serologija na ehinokoka je pokazala protitelesa IHA 1:4096 in pozitiven potrditveni test. Po 8 mesecih so se izboljšale vrednosti seroloških preiskav (IHA pozitivna 1:512). Dečka smo nato sledili na 6 mesecev. Jetrni testi so bili vseskozi v mejah normale, $v$ seroloških testih pa ni bilo dinamike. Cista je bila na kontrolnem UZ manjša, stena je kalcinirala $(20 \mathrm{~mm})$.

\section{Razpravljanje}

Hidatidno bolezen, ki jo povzroča pasja trakulja ehinokok, glede na klinično sliko razdelimo $v$ dve kategoriji. Prva je cistična hidatidna bolezen, ki jo povzroča Echinococcus granulosus, druga pa alveolna hidatidna bolezen, 
ki jo povzroča Echinococcus multilocularis. Redkejša povzročitelja sta E. vogeli in E olighartus $(4,5)$.

V raziskavi na vzorcu 338 otrok v endemskem področju $v$ Maroku so ugotovili, da je delež okuženih večji v ruralnih $(74,3 \%)$ področjih, kar pripisujejo pomanjkljivi ozaveščenosti glede pomembnosti higiene rok pri prenosu okužbe in skupnem bivanju s psi. Več okuženih otrok je bilo moškega spola, kar v retrospektivni raziskavi treh pediatričnih ustanov pripisujejo dejstvu, da fantje vsakodnevno pri izvajanju dejavnosti več časa preživijo v zunanjemu okolju, kar pomeni večjo verjetnost okužbe. Najpogosteje so zbolevali otroci v starostni skupini 7-11 let, pogosteje pa je bil prizadet izključno en organ $(94,4 \%)(1,4)$. Pomembna je tudi ugotovitev 10-letne retrospektivne raziskave hidatidnih cist pri otrocih, da je imelo $10 \%$ otrok pozitivno družinsko anamnezo (3).

Odrasel parazit Echinococcus granulosus je velik $2-7 \mathrm{~mm}$ in sestavljen iz 2-6 segmentov. Živi v črevesu okuženih mesojedih živali in ne povzroča težav. Človek se okuži z zaužitjem jajčec, ki jih živali izločajo z iztrebki posredno preko dlake, kontaminirane vode, zelenjave in sadja $(1,4)$. Z ehinokokom se pogosto okužimo v otroštvu, a je potrebno precej časa, kar 12 mesecev do več let, da ciste dovolj zrastejo in povzročajo simptome. Bolezen se med ljudmi ne prenaša, saj človek jajčec ne izloča z blatom (1).

Ličinka se razvije v črevesju, natančneje v dvanajstniku, ter preko črevesne stene, krvi in limfe prispe $v$ različne organe (jetra, pljuča, vranico, kosti, genitourinarni trakt, žolčnik, nadledvični žlezi, možgane, srce, mišice) in tvori ciste (3-5). Jetra so s prenosom preko portalne vene za ličinko prvi filter, kjer ta umre ali pa se razvije v hidatidno cisto. Včasih se ličinka prebije skozi jetra in nadaljuje pot v pljuča, ki so drugi filter, nato pa se lahko razširi še na druge organe in tkiva. Ličinka lahko s širjenjem preko limfe portalno veno tudi zaobide in verjetno je tudi takšna širitev ključna za nastanek ciste $v$ vranici. Teorija nastanka hidatidne ciste $v$ možganih je najverjetneje povezana s prehodom parazita preko odprtega arterioznega voda $(1,4)$. $\checkmark$ približno 5-13 \% je prizadetih več organov hkrati. Jetrna hidatidna cista naj bi v prvih šestih mesecih zrasla za $0,1-1 \mathrm{~cm}$, nato pa vsako leto $2-3 \mathrm{~cm}$, torej v povprečju $1-5 \mathrm{~cm}$ na leto $(4,6)$.

Pogosto mesto nastanka cist pri otrocih so pljuča in jetra, medtem ko je pri $70 \%$ odraslih hidatidna cista v desnem jetrnem režnju. Okrog cist nastane zadebeljena fibrozna kapsula. Jajčeca plavajo $v$ tekočini ciste ali so pritrjene na steno. Znotraj ciste lahko nastane tudi manjša hčerinska cista. Tekočina v zdravi cisti je brezbarvna in vodene strukture. Po medikamentoznem zdravljenju ali bakterijski okužbi tekočina postane gosta (3-5).

Ciste v jetrih večinoma ne povzročajo simptomov ali spontano regredirajo. Simptomatske ciste lahko povzročijo bolečine v trebuhu, ki so najpogostejši simptom jetrne hidatidne ciste. Bolezen se lahko kaže tudi s povečanim obsegom trebuha, tipno maso v trebuhu in bruhanjem. Zlatenica je pri otrocih redka (4). Do resnih zapletov lahko pride, če ciste pritiskajo na okolne strukture in se razlijejo, bodisi spontano ali iatrogeno. Večje težave povzročajo tudi ciste $v$ možganih (povišan znotrajlobanjski tlak, glavobol, bruhanje), kosteh (zlomi) in reproduktivnih organih (neplodnost). Pojav ciste v pljučih (najpogosteje $v$ desnem spodnjem lobusu) povzroča bolečino $v$ prsnem košu, kašelj, ki je najpogostejši simptom, ali hemoptizo. Pri ledvični hidatidozi ugotavljamo piurijo, hematurijo, vztrajajočo vročino, količne bolečine, ledvične kamne in arterijsko hipertenzijo. Ob prizadetosti srca se pojavljajo bolečine v prsnem košu, slabost, palpitacije, dispneja in aritmija. Razlitje ciste lahko povzroči anafilaksijo, nevarno pa je tudi zato, ker se lahko iz vsakega razlitega in raznesenega jajčeca razvije nova cista $(4,5)$.
Diagnozo postavimo na podlagi klinične slike (hepatomegalije, tipne mase v trebuhu) ter slikovnih in seroloških preiskav. UZ preiskava je najboljše orodje tako za postavitev diagnoze kot tudi za spremljanje zdravljenja ciste v jetrih. UZ ima $v$ primerjavi s preiskavo $C T$, ki je bolj natančna, 85-odstotno specifičnost. Prikažemo si lahko interne membrane hidatidne ciste in ehogen material, t. i. hidatidni pesek. $Z$ rentgensko (RTG) slikovno preiskavo si lahko prikažemo hidatidno cisto v pljučih in kosteh, s CT pa natančneje razlikujemo med alveolno obliko in cistično obliko hidatidne bolezni (3-5).

S serološkimi preiskavami lahko diagnozo potrdimo, a so lahko $v$ več kot 50 \% lažno negativne. Po podatkih 10-letne retrospektivne raziskave na vzorcu otrok je bil indirektni hemaglutinacijski test (IHA) pozitiven le pri 60 $\%$ testiranih otrok s hidatidno cisto. Kot test $z$ visoko občutljivostjo (95,5\%) velja test ELISA - IgG, ki ga v Sloveniji uporabljamo kot potrditveni test po pozitivni indirektni hemaglutinaciji (7).

Izsledki raziskav kažejo, da je pri kar $30 \%$ od 18 otrok prisotna eozinofilija. Povprečne vrednosti v odstotkih so bile $4,8 \%+/-1,3 \%(3,4)$.

$\checkmark$ diferencialni diagnozi pomislimo na benigne ciste jeter ali jetrni absces.

Zdravljenje je odvisno od otrokove starosti, strukture ciste ter lokacije in velikosti. Zdravimo s kirurško odstranitvijo ciste, postopkom PAIR (perkutana aspiracija, injekcija cidne raztopine in reaspiracija) in z zdravili, bodisi kot samostojno zdravljenje ali v kombinaciji z drugimi načini. Pri hidatidni cisti $v$ jetrih priporočamo zdravljenje $s C T$ ali UZ vodenim PAIR (3). Glede na klasično kirurško odstranitev ciste, ki je prva izbira zdravljenja pri pljučni hidatidni cisti, ima to zdravljenje v kombinaciji z albendazolom manj neželenih učinkov in krajšo hospitalizacijo. PAIR je bolj učinkovit pri zmanjšanju ciste kot zgolj albendazol, prav tako tudi bolj uspešno zmanjša simptome $(3,5)$. $\checkmark$ raziskavi, povezani z cistično hidati- 
dno boleznijo, ki je zajemala 187 otrok, svetujejo tudi algoritem zdravljenja. Po algoritmu naj bi 1-4 tedne pred operativnim posegom pričeli z zdravljenjem $z$ albendazolom in bolnike, ki so imeli opravljeno cistektomijo ciste, manjše od $10 \mathrm{~cm}$, sledili tudi dolgoročno. Pri cistektomiji ciste, večje od $10 \mathrm{~cm}$, po posegu svetujejo 1- do 3-mesečno zdravljenje $z$ albendazolom. Bolnike po odstranitvi organa zaradi zapletene ciste sledimo dolgoročno, bolnike z neaktivno ali kalcificirano cisto sledimo s slikovnimi preiskavami (8).

Kirurška odstranitev ciste je na mestu pri velikih jetrnih cistah z vsebnostjo hčerinskih cist, pri superficialno ležečih cistah, ki lahko rupturirajo, pri okuženih cistah, ki komunicirajo z biliarnim traktom, pri cistah, večjih od $10 \mathrm{~cm}$, pri sekundarno okuženih ali krvavečih cistah ter pri cistah v možganih, ledvicah, kosteh in pljučih. Za boljši učinek zdravljenja odstranimo celotno ovojnico, vsebino votline, ki ostane, pa zapremo z omentumom. Podatki primerjave med odprtim kirurškim posegom in laparoskopskim posegom pri zdravljenju otrok s hidatidno cisto jeter kažejo, da je laparoskopska operacija bolj varna in kratkotrajna ter z manj pooperativnimi zapleti $(3,5,9)$. Izsledki nekaterih raziskav kažejo, da je pri otrocih zaradi dobre regeneracije pljuč in velike verjetnosti ponovne okužbe predvsem v endemskih področjih na prvem mestu zdravljenja hidatidoze pljuč cistektomija (3).

Pri ostalih je indicirano zdravljenje $z$ albendazolom v odmerku 10-15 mg/ kg 1- do 2-krat na dan za 1-6 mesecev oralno (največji odmerek je 800 mg/ dan). Zadovoljiv odgovor na zdravljenje dosežemo pri 40-60 \% bolnih (5, 10). Zdravljenje z zdravili svetujemo pri zdravljenju neoperabilnih, diseminiranih cist ali ponovitvi bolezni. Povprečen čas zdravljenja $z$ albendazolom naj bi bil 15,5 meseca +/- 1,5 meseca. Daljši čas zdravljenja je bil po literaturi potreben pri otrocih s prizadetostjo drugih organov in ne jeter ali pljuč $(3,4)$. Neželeni učinki zdravljenja z

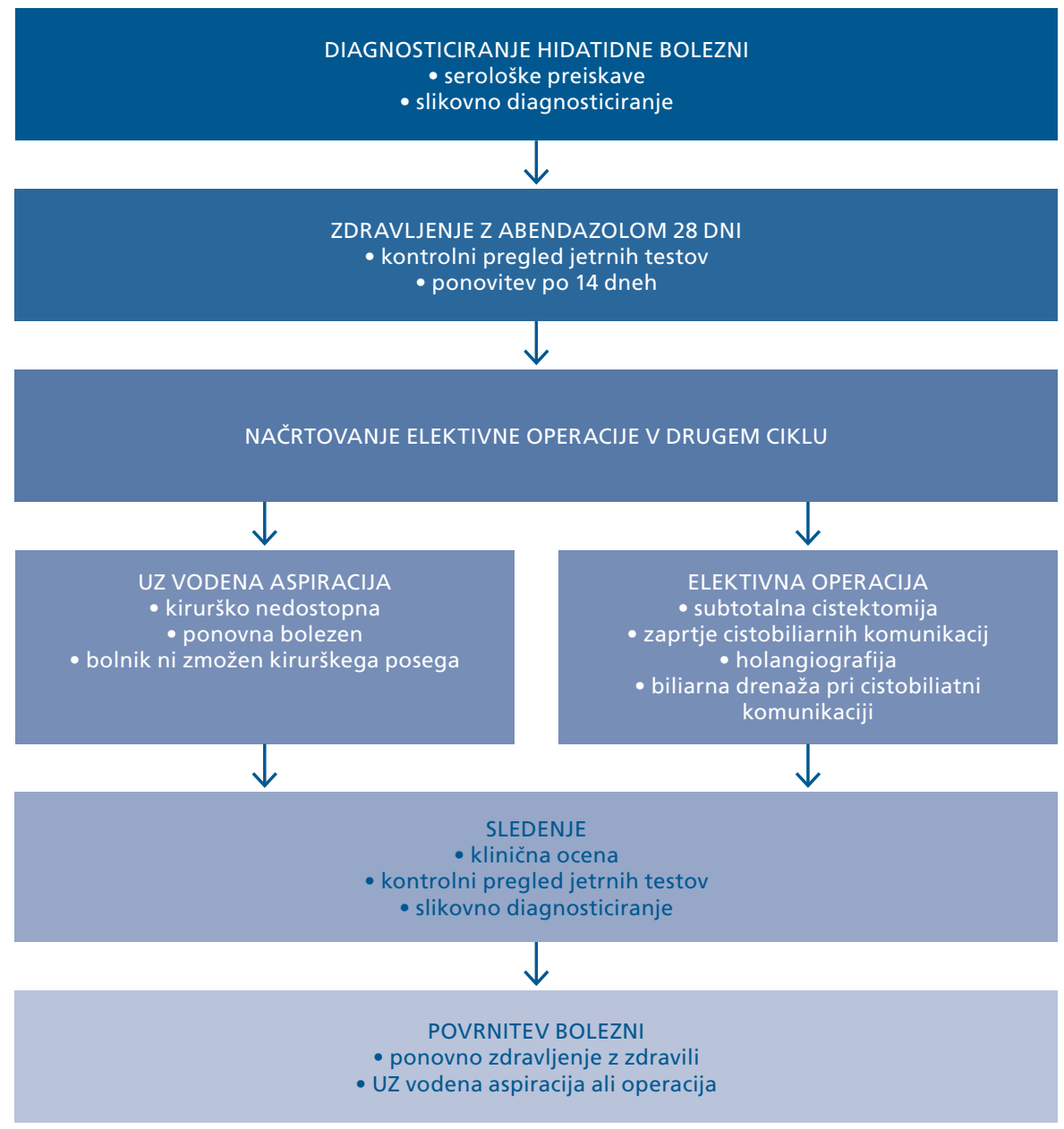

SLIKA 1. ALGORITEM DIAGNOSTICIRANJA IN ZDRAVLJENJA HIDATIDNE BOLEZNI (PRIREJENO PO 11). FIGURE 1. ALGORITHM FOR THE DIAGNOSIS AND TREATMENT OF HYDATID DISEASE (ADAPTED FROM 11). 
albendazolom so alopecija, blagi prebavni simptomi in povišane vrednosti jetrnih transaminaz (5). Po podatkih iz retrospektivne študije, ki je vključevala 50 otrok, zdravljenih z albendazolom, je prišlo ob zdravljenju $z$ albendazolom do porasta transaminaz le v $2 \%$. $\checkmark$ tem primeru svetujemo prekinitev zdravljenja (3). Zaradi levkopenije med zdravljenjem priporočamo kontrolni pregled krvi na 2 tedna (5).

Zdravljenje hidatidne bolezni je v povprečju dolgotrajno, od 3 mesecev do 2,5 leta $(3,5)$. Brez zdravljenja ciste napredujoče rastejo, lahko pa pride do njenega spontanega umika in odmrtja ciste, ki nato kalcificira. Delno kalcificirajoča cista ne pomeni odmrtja parazita (4).

Glede napovedi izida so bolj ugodne manjše in manj kompleksne ciste, mlajše od 2 let (5). Do Izsledki 10-letne retrospektivne raziskave kažejo, da do relapsov bolezni pride predvsem ob prizadetosti drugih organov (in ne jeter ali pljuč, kar je najbolj pogosto) (3).

Preventivno priporočamo čim manj stikov s psi v endemskih področjih, redno umivanje rok, umivanje živil in pregled živil s strani inšpektorata.

V Sloveniji so živali, ki jih uporabljamo za hrano, pod obveznim nadzorom Uprave za varno hrano, veterinarstvo in varstvo rastlin (UVHVVR). Potrebni so tudi redni pregledi psov pri veterinarju, psi pa morajo tudi redno prejemati zdravila proti zajedalcem.

\section{Zaključek}

Po podatkih iz literature je cistična ehinokokoza v endemskih področjih pogosta parazitoza, na katero moramo pomisliti ob značilnih kliničnih znakih ali naključni najdbi cističnih sprememb s slikovnimi diagnostičnimi metodami. $V$ povprečju pogosteje zbolevajo otroci, predvsem fantje v ruralnih področjih. Obdobje med okužbo z ehinokokom in klinično prezentacijo, ki je odvisna predvsem od lege ciste in njene velikosti, lahko traja tudi več let. Diagnoza temelji na klinični sliki in slikovnem diagnosticiranju ter seroloških preiskavah. Napoved izida bolezni je odvisna od razsejanosti okužbe ter lege in kompleksnosti ciste.

$\checkmark$ predstavljenem kliničnem primeru je bila jetrna cista odkrita naključno, dečka pa so obravnavali in zdravili v skladu s priporočili retrospektivnih raziskav pri otrocih. Zdravljenje je bilo uspešno.

\section{Literatura}

1. Amachmid O, El Guamri Y, Zenjari K, Bouhout $\mathrm{S}$, Ait Moh M, Boraam F et al. The pattern of cystic echinococcosis in children in an endemic area in Morocco. J Parasit Dis 2019; 43 (2): 209-14

2. Moosazadeh M, Abedi G, Mahdavi SA, Shojaee J, Charkame A, Afshari M. Epidemiological and clinical aspects of patients with hydatid cyst in Iran. J Parasit Dis 2017; 41(2): 356-60.

3. Sismanlar Eyüboglu T, Ramaslı Gürsoy T, Tana Aslan A, Pekcan S, Budakoglu IÍ. Ten-year follow -up of children with hydatid cysts. Turk Pediatri Ars 2019; 54 (3): 173-8.

4. Gupta R, Sharma SB, Prabhakar G, Mathur P. Hydatid disease in children: our experience. Formos J Surg 2014; 47: 211-20.

5. Kliegman RM, Stantom BF, Schor NF, St. Game JW, Behrman RE. Nelson textbook of pediatrics. 19th ed. Philadelphia: Saunders Elsevier; 2011.

6. Pakala T, Molina M, Y Wu G. Hepatic echinococcal cysts: a review. J Clin Transl Hepatol 2016; 4(1): 39-46.

7. El-Ghareeb AS, Waked NM, Al-Feky HM. Clinical and parasitological studies on pulmonary and hepatic hydatid cysts in hospitalized children and adults (abstract). J Egypt Soc Parasitol 2016; 46(1): 9-18.

8. Minaev SV, Gerasimenko IN, Kirgizov IV, Shamisev AM, Bykov NI, Shamisev JA. Laparoscopic treatment in children with hydatid cyst of the liver. World J Surg 2017; 41(12): 3218-23.

9. Yuan WH, Lee RC, Chou YH, Chiang JH, Chen YK, Hsu HC. Hydatid cyst of the liver: A case report and literature review. Kaohsiung J Med Sci 2005; 21: 418-23.

10. Oral A, Yigiter M, Yildiz A, Yalcin O, Dikmen $\mathrm{T}$, Eren $\mathrm{S}$ et al. Diagnosis and managment of hydatid liver disease in children: a report of 156 patients with hydatid disease. J Pediatr Surg 2012; 47(3): 528-34.

11. Silva MA, Mirza DF, Bramhall SR, Mayer $A D$, Mcmaster P, Buckels JAC. Treatment of hydatid disease of liver. Dig Surg 2004; 21: 227-34.
Petra Golob, dr. med. (kontaktna oseba/contact person)

Splošna bolnišnica Murska Sobota

Ulica dr. Vrbnjaka 6

9001 Murska Sobota, Slovenija

e-naslov: golobicka85@yahoo.com

Katja Zemljarič, dr. med.

Splošna bolnišnica Murska Sobota,

Murska Sobota, Slovenija

asist. dr. Jernej Brecelj, dr. med.

Klinični oddelek za gastroenterologijo,

hepatologijo in nutricionistiko,

Pediatrična klinika, Univerzitetni kčinični

center Ljubljana in

Katedra za pediatrijo, Medicinska

fakulteta, Univerza v Ljubljani, Ljubljana,

Slovenija

prispelo / received: 24. 7. 2020

sprejeto / accepted: 2. 11. 2020

Golob P, Zemljarič K, Brecelj J. Cistična hidatidna bolezen pri otroku: prikaz primera. Slov Pediatr 2020; 27(4): 183-187. https://doi.org/10.38031/ slovpediatr-2020-4-04 